\title{
An Anatomical Point to Start Transection in Laparoscopic Sleeve Gastrectomy
}

\begin{abstract}
Keywords: Sleeve gastrectomy; Landmark; Antrum
Abstract

Introduction: Laparoscopic Sleeve Gastrectomy (LSG) has become a preferred primary bariatric surgical approach. However, some technical aspects still lack standardization, including the distance from the pylorus at which the resection should start. The goa of this study was to identify an anatomical landmark to aid surgeons in identifying a reference point.

Materials and methods: Patients undergoing bariatric surgery were enrolled prospectively. Inclusion criteria were age over 18, BMI > 35 $\mathrm{kg} / \mathrm{m} 2$, and the absence of any prior upper abdominal surgery. After liver retraction, an imaginary line was drawn from the right side of the esophagus through the incisura angularis to the greater curvature, and the distance from this point to the pylorus was recorded. The measure and its correlations with gender, BMI and height were analyzed.

Results: Out of 129 patients, 101 (78.3\%) were female. Mean BMl was $45.4 \mathrm{~kg} / \mathrm{m} 2$. The average distance measured was $6.95 \mathrm{~cm} 15-9$, $\mathrm{SD}=0.75)$. There was no correlation between this distance and either BMI ( $r=0.06)$ or height $(r=0.2)$. There was a $0.4 \mathrm{~cm}$ difference between men and women $(7.3$ vs. $6.9 \mathrm{~cm}), p=0.03$. In $93.8 \%$ of the cases, the distance was between 6 and $8 \mathrm{~cm}$.

Conclusion: A line starting on the right side of the esophagus through the incisura angularis to the intersection with the greater curvature establishes a point that can be used reliably as a reference to start transection for LSG. It also may be useful when the pylorus is difficult to visualize, as in patients who are super obese or have adhesions.
\end{abstract}

\section{Introduction}

Bariatric procedures have emerged as the only effective and durable treatment for morbid obesity [1]. Among them, Laparoscopic Sleeve Gastrectomy (LSG) has become a preferred primary weight loss surgery [2,3]. However, the technique is not performed the same way by different bariatric surgeons [4]. The size of the bougie used for calibration, the necessity and options for reinforcing the staple line, and the section shape at the gastroesophageal junction has not been standardized. The distance from the pylorus to the first line of section also varies, with most preferring 2 to $8 \mathrm{~cm}$ [5-9].

Surgeons may choose where to start stapling by using a measuring device like a ruler, a length of suture, or an instrument of known length like a laparoscopic grasper [10].

The goal of this study was to analyze an anatomical point to help surgical teams to determine the starting point for stapling in LSG.

\section{Materials and Methods}

From January 2014 to July 2014, 125 patients were recruited for this trial. Inclusion criteria were a BMI over $35 \mathrm{~kg} / \mathrm{m}^{2}$, age over 18 , and the absence of prior upper abdominal surgeries.

\section{Journal of}

Obesity and

Bariatrics

\section{Patricio Cal*, Luciano Deluca, Tomás Jakob, Liliana Parasporo and Ezequiel O. Fernández}

Centro de Rehabilitación Quirúrgica de la Obesidad, Buenos Aires, Argentina

\section{*Address for Correspondence}

Patricio Cal, Centro de Rehabilitación Quirúrgica de la Obesidad, Riobamba 429, Buenos Aires, Argentina, Tel: (54)-9-11-3470-5818; E-mail: pcal@bariatrica.com.ar

Submission: 27 June, 2017

Accepted: 28 July, 2017

Published: : 04 August, 2017

Copyright: $\odot 2017$ Cal P, et al. This is an open access article distributed under the Creative Commons Attribution License, which permits unrestricted use, distribution, and reproduction in any medium, provided the original work is properly cited.

All patients received dietary counseling for at least four months and underwent a 2 weeks low-calorie diet. The pre-surgical goal was $10 \%$ total body weight reduction.

After pneumoperitoneum was achieved, 5 trocars were placed and the liver was retracted. Prior to any gastric manipulation, a 10 $\mathrm{cm}$ ruler graded at $5 \mathrm{~mm}$ intervals was inserted and an edge placed on the proximal side of the pylorus, running over the greater curvature. An imaginary line was then drawn starting on the right side of the esophagus through the incisura angularis to the intersection with the greater curvature, where the measurement was taken (Figure 1).

All measures were performed by two surgeons with personal experience performing over 1000 bariatric surgeries. A written consent was obtained from all patients.

Data collected included the recorded measurement and the patient's gender, height and BMI. Continuous variables were described as means, plus range and SD. Categorical values were expressed using absolute values and percentages. Differences between groups were tested using independent samples t-tests. Spearman's correlation coefficients were calculated to identify and quantify any correlations. A p-value less than 0.05 was considered statistically significant. PAWS v.18 was used as the statistical software.

\section{Results}

A total of 129 patients were included: 101 women (78.3\%) and 28 men (21.7\%). Anthropometric data are summarized in Table 1. The mean BMI was $45.4 \mathrm{~kg} / \mathrm{m}^{2}$ (35.9-79.5), age 42.4 (35.9-79.5), weight

Table 1: Antropometric data.

\begin{tabular}{|l|l|l|l|}
\hline & Mean & Range & SD \\
\hline Weight & 122.4 & $88.5-206$ & 23.9 \\
\hline Height & 1.64 & $1.48-1.97$ & 0.09 \\
\hline BMI & 45.4 & $35.9-79.5$ & 6.8 \\
\hline Age & 42.4 & $16-66$ & 10.2 \\
\hline Gender (M:F) & $79.5: 20.5$ & & \\
\hline
\end{tabular}




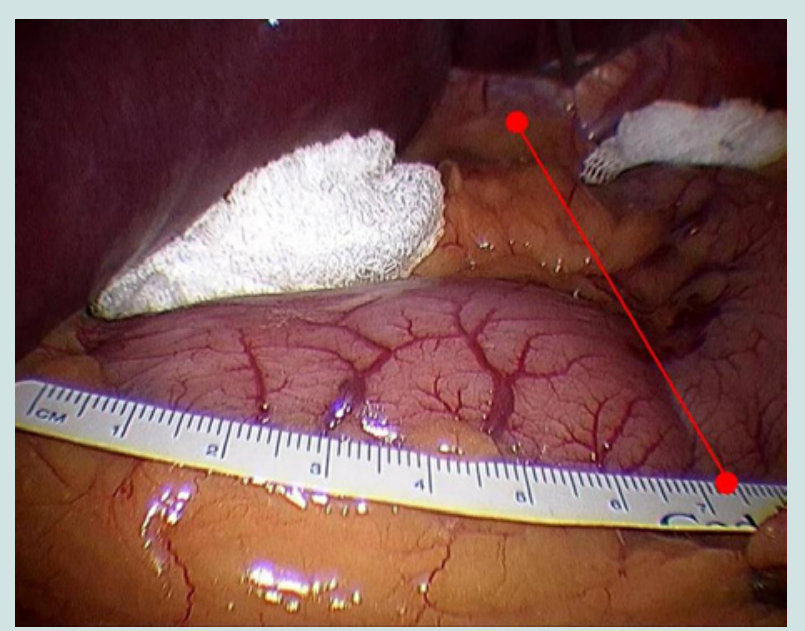

Figure 1: Measure taking.

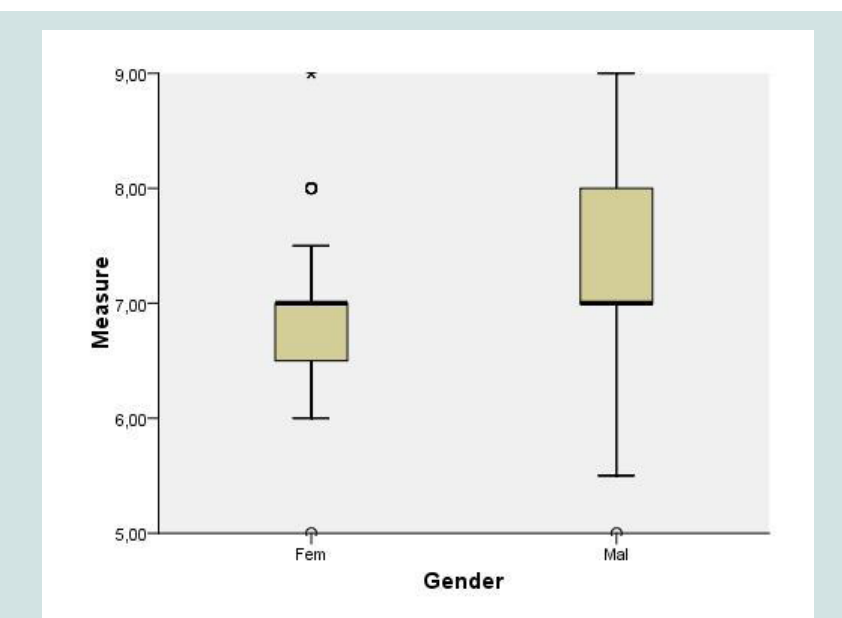

Figure 2: Difference between genders.

$122.4 \mathrm{~kg}(88.5-206)$ and height $1.64 \mathrm{~m}$ (1.48-1.97). The recorded measurement was a mean $6.95 \mathrm{~cm}(5-9 \mathrm{~cm}, \mathrm{SD}=0.75)$ in length. There was no correlation between this distance and either BMI $(r=0.06)$ or height $(\mathrm{r}=0.20)$. The mean distance in males was $7.3 \mathrm{~cm}(\mathrm{SD}=0.99)$ versus $6.9 \mathrm{~cm}$ in females $(\mathrm{SD}=0.64), \mathrm{p}=0.03$ (Figure 2). Dividing patients into three groups according to height $(<1.60 \mathrm{~m}, 1.60-1.65$ $\mathrm{m},>1.65 \mathrm{~m}$ ), the distance was $6.8,7.0$ and $7.0 \mathrm{~cm}$, respectively (NS). Categorizing patients into three groups by BMI $(<41,41-47,>47)$, the mean distance measured was $6.9,6.9$ and 7.0 (NS). In $93.8 \%$ of patients, the distance was between 6.0 and $8.0 \mathrm{~cm}$.

\section{Discussion}

LSG has proven to be an effective bariatric surgery, with acceptable morbidity and long-term weight loss relative to other procedures $[11,12]$. Its mechanism of action seems to involve a combination of gastric restriction, hormonal effects, and changes in gastric motility and eating habits [13].

Certain technical issues remain controversial with this surgery, however. One of the controversies is the distance from the pylorus at which gastric sectioning should begin [4].
The most conservative surgeons prefer to initiate it more than $4 \mathrm{~cm}$ from the pylorus [7-9]. This would improve gastric emptying by preserving its contractile function, also decreasing intraluminal pressure. As the integrity of the vagal nerve remains, and no pyloroplasty is performed, it would appear safer to resect the antrum farther from the pylorus [4].

Other authors begin the division $2 \mathrm{~cm}$ from the pylorus. They assume that, since this a restrictive technique, resection should be more aggressive [6].

Three recent studies compared $2 \mathrm{~cm} v s .6 \mathrm{~cm}$ antral resection. Both Abdallah et al. and Obeidat et al. found better weight loss and less weight regained at 2 years when starting resection $2 \mathrm{~cm}$ from the pylorus, whereas ElGeide et al. failed to identify any differences over one year of follow up [14-16]. ElGeide et al. also described a higher incidence of vomiting within the more extensive resection group over the first 6 post-operative months [15].

GERD is also a concern when performing this surgery [17-21]. By reducing intra-abdominal pressure and acid production, and increasing gastric emptying, LSG tends to improve reflux [22-25]. However, technical errors, decreased lower esophageal sphincter pressure, and increased pyloric or intraluminal pressure could increase GERD $[21,22,24,25]$. The implications behind the amount of antrum resected are unknown. Abdallah et al. described no significant impact of extent of antral resection on GERD [14]. Obeidat et al. reported more reflux ( $11.1 \%$ vs. $7.1 \%)$ when a larger antrum was left in place [16].

There are different ways in which a surgeon may determine where to start a sleeve gastrectomy. Using a ruler, a piece of suture, or an instrument of known length are some of the alternatives. However, identifying the pylorus is not always possible, especially in patients with prior surgeries. Also, introducing a ruler and directly measuring distances is time consuming. Previously, Clapp described the second branch of the right gastroepiploic vessel as a relatively constant anatomical landmark, at a mean of $4.6 \mathrm{~cm}$ from the pylorus [10]. However, vessels are sometimes hard to visualize in obese patients, and adhesions are an obstacle to ensuring which vessel is being seen.

The current study located an anatomical point that can be trusted as a reference. Our practice includes using this mark to determine where to place the first staple [26]. It has been easy to visualize and practical in the super obese and patients with prior biliary surgeries. Although the importance of the extent of antrum resection is yet to be defined, our proposed landmark might be useful in everyday practice.

\section{Conclusion}

A line starting on the right side of the esophagus through the incisura angularis to the intersection with the greater curvature establishes a point that can be used reliably as a reference to start transection for LSG. It also may be useful when the pylorus is difficult to visualize, as in patients who are super obese or have adhesions.

\section{References}

1. Sjöström L (2013) Review of the key results from the Swedish Obese Subjects (SOS) trial - a prospective controlled intervention study of bariatric surgery. $J$ Intern Med 273: 219-234.

2. Angrisani L, Santonicola A, lovino $P$, Formisano G, Buchwald $H$, et al. (2015) Bariatric surgery Worldwide 2013. Obes Surg 25: 1822-1832. 
Citation: Cal P, Deluca L, Jakob T, Parasporo L, Fernández EO. An Anatomical Point to Start Transection in Laparoscopic Sleeve Gastrectomy. J Obes Bariatrics. 2017;4(1): 3.

3. Rosenthal RJ, International Sleeve Gastrectomy Expert Panel, Diaz AA Arvidsson D, Baker RS, et al. (2012) International sleeve gastrectomy expert panel: best practice guidelines based on experience of $>12,000$ cases. Surg Obes Relat Dis 8: 8-19.

4. Ferrer-Márquez M, Belda-Lozano R, Ferrer-Ayza M (2012) Technical controversies in laparoscopic sleeve gastrectomy. Obes Surg 22 182-187.

5. Mognol P, Chosidow D, Marmuse JP (2005) Laparoscopic sleeve gastrectomy as an initial bariatric operation for high-risk patients: initial results in 10 patients. Obes Surg 15: 1030-1033.

6. Baltasar A, Serra C, Pérez N, Bou R, Bengochea M, et al. (2005) Laparoscopic sleeve gastrectomy: a multi-purpose bariatric operation. Obes Surg 15: 1124 1128.

7. Givon-Madhala O, Spector R, Wasserberg N, Beglaibter N, Lustigman $\mathrm{H}$ et al. (2007) Technical aspects of laparoscopic sleeve gastrectomy in 25 morbidly obese patients. Obes Surg 17: 722-727.

8. Silecchia G, Boru C, Pecchia A, Rizzello M, Casella G, et al. (2006) Effectiveness of laparoscopic sleeve gastrectomy (first stage of biliopancreatic diversion with duodenal switch) on co-morbidities in super-obese high-risk patients. Obes Surg 16: 1138-1144

9. Cottam D, Qureshi FG, Mattar SG, Sharma S, Holover S, et al. (2006) Laparoscopic sleeve gastrectomy as an initial weight-loss procedure for highrisk patients with morbid obesity. Surg Endosc 20: 859-863.

10. Clapp B (2013) Anatomic landmarks in the sleeve gastrectomy. JSLS 17 388-389.

11. Himpens J, Dapri G, Cadière GB (2006) A prospective randomized study between laparoscopic gastric banding and laparoscopic isolated sleeve gastrectomy: results after 1 and 3 years. Obes Surg 16: 1450-1456.

12. Peterli R, Borbély Y, Kern B, Gass M, Peters T, et al. (2013) Early results of the Swiss Multicentre Bypass or Sleeve Study (SM-BOSS): a prospective randomized trial comparing laparoscopic sleeve gastrectomy and Roux-en-Y gastric bypass. Ann Surg 258: 690-694.

13. Papailiou J, Albanopoulos K, Toutouzas KG, Tsigris C, Nikiteas N, et al. (2010) Morbid obesity and sleeve gastrectomy: how does it work? Obes Surg 20: 1448-1455.

14. Abdallah E, El Nakeeb A, Youssef T, Abdallah H, Ellatif MA, et al. (2014) Impact of extent of antral resection on surgical outcomes of sleeve gastrectomy for morbid obesity (a prospective randomized study). Obes Surg 24: $1587-1594$
15. ElGeidie A, ElHemaly M, Hamdy E, El Sorogy M, AbdelGawad M, et al. (2015) The effect of residual gastric antrum size on the outcome of laparoscopic sleeve gastrectomy: a prospective randomized trial. Surg Obes Relat Dis 11: 997-1003.

16. Obeidat F, Shanti H, Mismar A, Albsoul N, Al-Qudah M (2015) The magnitude of antral resection in laparoscopic sleeve gastrectomy and its relationship to excess weight loss. Obes Surg 25: 1928-1932.

17. Parikh M, Issa R, McCrillis A, Saunders JK, Ude-Welcome A, et al. (2013) Surgical strategies that may decrease leak after laparoscopic sleeve gastrectomy: a systematic review and meta-analysis of 9991 cases. Ann Surg 257: $231-237$.

18. Schneider JH, Küper M, Königsrainer A, Brücher B (2009) Transient lower esophageal sphincter relaxation in morbid obesity. Obes Surg 19: 595-600.

19. Tai CM, Huang CK, Lee YC, Chang CY, Lee CT, et al. (2013) Increase in gastroesophageal reflux disease symptoms and erosive esophagitis 1 year after laparoscopic sleeve gastrectomy among obese adults. Surg Endosc 27: 1260-1266

20. Daes J, Jimenez ME, Said N, Daza JC, Dennis R (2012) Laparoscopic sleeve gastrectomy: symptoms of gastroesophageal reflux can be reduced by changes in surgical technique. Obes Surg 22: 1874-1879.

21. Carabotti M, Silecchia G, Greco F, Leonetti F, Piretta L, et al. (2013) Impact of laparoscopic sleeve gastrectomy on upper gastrointestinal symptoms. Obes Surg 23: 1551-1557.

22. Hamoui N, Anthone GJ, Kaufman HS, Crookes PF (2006) Sleeve gastrectomy in the high-risk patient. Obes Surg 16: 1445-1449.

23. Nocca D, Krawczykowsky D, Bomans B, Noël P, Picot MC, et al. (2008) A prospective multicenter study of 163 sleeve gastrectomies: results at 1 and 2 years. Obes Surg 18: 560-565.

24. Braghetto I, Lanzarini E, Korn O, Valladares H, Molina JC, et al. (2010) Manometric changes of the lower esophageal sphincter after sleeve gastrectomy in obese patients. Obes Surg 20: 357-362.

25. Melissas J, Koukouraki S, Askoxylakis J, Stathaki M, Daskalakis M, et al (2007) Sleeve gastrectomy: a restrictive procedure? Obes Surg 17: 57-62.

26. Cal P, Deluca L, Jakob T, Fernández E (2016) Laparoscopic sleeve gastrectomy with 27 versus $39 \mathrm{Fr}$ bougie calibration: a randomized controlled trial. Surg Endosc 30: 1812-1815. 